\title{
An editorial perspective: new team, aims and scope and advances of EWCO
}

\author{
Jessica Zhang ${ }^{1} \cdot$ John Evans $^{2} \cdot$ Hector Gomez $^{3} \cdot$ Kris van der Zee $^{4}$ \\ Published online: 3 February 2022 \\ (c) The Author(s), under exclusive licence to Springer-Verlag London Ltd., part of Springer Nature 2022
}

EWCO was founded by Ted Belytschko and Steven J. Fenves in 1985 as an International Journal for Simulation-Based Engineering. Mark Shephard took over as the Editor-in-Chief in 1998 and ran it until February 2021. EWCO published 37 volumes, 142 issues and 2016 articles during 1985-2021. With special thanks to Shephard's tremendous efforts in latest years, the impact factor of EWCO has increased to 7.963 (2020) and the number of downloads reached 143,420 (2020).

Since March 2021, we have been building the new editorial team as shown on the EWCO website. In addition to the Editor-in-Chief (Jessica Zhang), EWCO welcomed its three Associate Editors (John Evans, Hector Gomez and Kris van der Zee). A new Advisory Board was setup with four prominent world-leading researchers in simulation-based engineering, including Thomas J.R. Hughes, Wing Kam Liu, Glaucio H. Paulino and Mark Shephard. The Editorial Board was enlarged with 19 new members.

The aims and scope were updated in 2021. In particular, EWCO

- Publishes original papers and authoritative state-of-theart reviews on the technologies supporting simulationbased engineering;

- Focuses on the development of new computing methods, algorithms and workflows, addressing significant computational challenges;

- Emphasizes technologies that support a wide range of engineering applications; and

- Welcomes novel cutting-edge research and algorithmbased software development.

\footnotetext{
Jessica Zhang

jessicaz@andrew.cmu.edu

Carnegie Mellon University, Pittsburgh, USA

University of Colorado Boulder, Boulder, USA

Purdue University, West Lafayette, USA

4 The University of Nottingham, Nottingham, UK
}

A list of topics/categories is provided on the submission website for the submitter to select, including adaptive simulation techniques; data-driven and hybrid modeling methods; design through analysis workflows; engineering software development; large-scale simulation methods; mesh generation; simulation-based optimization; simulation interactivity; visualization techniques; and other computational methods.

In recent years, the number of submissions has grown significantly. To accommodate large number of accepted articles, EWCO will publish 6 issues per year starting from 2022.

In 2021, EWCO secured four special issues on cuttingedge research organized by well-known researchers: Computational Modeling Based on Nonlocal Theory by Timon Rabczuk, Erkan Oterkus, Xiaoying Zhuang; Image-Based Methods in Computational Medicine by Adrian Buganza Tepole, Rafael Grytz, Maria Holland, Johannes Weickenmeier; Numerical Simulation for Additive Manufacturing Processes and Products by Alessandro Reali, Ferdinando Auricchio, Michele Chiumenti, Ernst Rank; and Special Issue UKACM 2022: Advances in Computational Mechanics by Kris van der Zee, Matteo Icardi, Jelena Ninic.

Together with US Association for Computational Mechanics (USACM), EWCO sponsored Best Female Presentation Award in the 16th U.S. National Congress on Computational Mechanics (USNCCM), July 25-29, 2021. Two junior faculty, three postdocs and two $\mathrm{PhD}$ students were selected as the winners or runners up.

We appreciate all the endless contributions from the authors, reviewers, editorial team and Springer supporting team (Shanthakumar Kulasekar, Kaaviya Haribabu, Allison Keene and Patrick Keefe), especially in such a difficult pandemic situation. Hope everyone stays well and we look forward to continuing to work with you in the years to come!

Publisher's Note Springer Nature remains neutral with regard to jurisdictional claims in published maps and institutional affiliations. 